\title{
Effect of exenatide on the pharmacokinetics of a combination oral contraceptive in healthy women: an open-label, randomised, crossover trial
}

Prajakti A Kothare ${ }^{1 *}$, Mary E Seger ${ }^{1}$, Justin Northrup ${ }^{1}$, Kenneth Mace ${ }^{1}$, Malcolm I Mitchell ${ }^{1}$ and Helle Linnebjerg ${ }^{2}$

\begin{abstract}
Background: Consistent with its effect on gastric emptying, exenatide, an injectable treatment for type 2 diabetes, may slow the absorption rate of concomitantly administered oral drugs resulting in a decrease in maximum concentration $\left(C_{\max }\right)$. This study evaluated the drug interaction potential of exenatide when administered adjunctively with oral contraceptives, given their potential concomitant use.

Methods: This trial evaluated the effect of exenatide co-administration on single- and multiple-dose pharmacokinetics of a combination oral contraceptive (ethinyl estradiol [EE] $30 \mu \mathrm{g}$, levonorgestrel [LV] $150 \mu \mathrm{g}$ $\left[\right.$ Microgynon $\left.30^{\circledR}\right]$ ). Thirty-two healthy female subjects participated in an open-label, randomised, crossover trial with 3 treatment periods (oral contraceptive alone, 1 hour before exenatide, 30 minutes after exenatide). Subjects received a single dose of oral contraceptive on Day 8 of each period and QD doses on Days 10 through 28. During treatment periods of concomitant usage, exenatide was administered subcutaneously prior to morning and evening meals at $5 \mu \mathrm{g}$ BID from Days 1 through 4 and at $10 \mu \mathrm{g}$ BID from Days 5 through 22. Single- (Day 8) and multiple-dose (Day 22) pharmacokinetic profiles were assessed for each treatment period.

Results: Exenatide did not alter the bioavailability nor decrease daily trough concentrations for either oral contraceptive component. No substantive changes in oral contraceptive pharmacokinetics occurred when oral contraceptive was administered 1 hour before exenatide. Single-dose oral contraceptive administration 30 minutes after exenatide resulted in mean (90\% Cl) $C_{\max }$ reductions of $46 \%$ (42-51\%) and $41 \%$ (35-47\%) for EE and LV, respectively. Repeated daily oral contraceptive administration 30 minutes after exenatide resulted in $C_{\max }$ reductions of $45 \%$ (40-50\%) and 27\% (21-33\%) for EE and LV, respectively. Peak oral contraceptive concentrations were delayed approximately 3 to 4 hours. Mild-to-moderate nausea and vomiting were the most common adverse events observed during the trial.
\end{abstract}

Conclusions: The observed reduction in $C_{\max }$ is likely of limited importance given the unaltered oral contraceptive bioavailability and trough concentrations; however, for oral medications that are dependent on threshold concentrations for efficacy, such as contraceptives and antibiotics, patients should be advised to take those drugs at least 1 hour before exenatide injection.

Trial registration: ClinicalTrials.gov: NCT00254800.

Keywords: exenatide twice daily, pharmacokinetics, oral contraceptive

\footnotetext{
* Correspondence: kotharep@yahoo.com

${ }^{1}$ Eli Lilly and Company, Lilly Corporate Center, Indianapolis, IN, USA

Full list of author information is available at the end of the article
} 


\section{Background}

Exenatide, a 39-amino acid peptide and antidiabetic agent known as a glucagon-like peptide-1 receptor agonist, has multiple glucoregulatory actions which are similar to those of endogenous glucagon-like peptide-1. In the European Union, it is an adjunctive therapy for patients with type 2 diabetes who are suboptimally controlled with metformin, a sulphonylurea, a thiazolidinedione, and combinations of metformin plus a sulphonylurea or metformin plus a thiazolidinedione. In the United States, exenatide is indicated as an adjunct to diet and exercise to improve glycaemic control in adults with type 2 diabetes mellitus. Following a subcutaneous dose (5 or $10 \mu \mathrm{g}$ BID), exenatide is rapidly absorbed with a time to peak concentration $\left(\mathrm{T}_{\max }\right)$ of approximately 2 hours, has a terminal half-life $\left(t_{1 / 2}\right)$ of 2.4 hours [1], and is predominantly eliminated by passive renal mechanisms [2]. Exenatide has been shown to reduce fasting and postprandial glucose by the combined contribution of glucose-dependent insulin secretion, suppression of glucagon secretion, and slowing of gastric emptying [3-5]. There is evidence that this treatment also reduces appetite [6] and energy intake [7].

Consistent with its pharmacological effect of slowing gastric emptying, exenatide may reduce the rate of absorption of concomitantly administered oral drugs. Drug-drug interaction studies with digoxin [8], warfarin [9], lovastatin [10], and lisinopril [11] have demonstrated that concomitant exenatide treatment reduced the maximum plasma concentrations $\left(C_{\max }\right)$ and delayed the $T_{\max }$ for these drugs, both of which are consistent with slowing of gastric emptying. Reductions in overall exposure (area under the curve $[\mathrm{AUC}]$ ) were only observed in the exenatide-lovastatin interaction study. However, given the known pharmacokinetic characteristics of exenatide, the potential for a CYP3A induction was considered unlikely and the observed results were considered to be related to incomplete characterization of the single-dose lovastatin AUC following exenatide dosing. Acetaminophen [12], a marker of gastric emptying, was studied with exenatide to understand how the relative timing of exenatide administration might change the magnitude of pharmacokinetic effects observed for orally administered drugs. In addition, this prior study provided information on the optimal timing for administration of other concomitant oral medications. Changes in the acetaminophen profile were not evident when acetaminophen was given 1 hour prior to the exenatide dose as the absorption process for acetaminophen had likely been completed before the onset of exenatide action. However, a reduced $\mathrm{C}_{\max }$ and delayed $\mathrm{T}_{\max }$ were observed when acetaminophen was given after exenatide administration; the magnitude of changes was greatest 1 to 2 hours after exenatide administration.

The present study evaluated the drug-drug interaction potential of exenatide with a widely used concomitantly administered combination oral contraceptive (OC) consisting of ethinyl estradiol (EE) and levonorgestrel (LV). The study included a treatment period in which OC was administered 30 minutes after exenatide, such that the anticipated time of peak exposure of the oral contraceptive would coincide with the maximum effect of slowed gastric emptying. A second treatment period with $\mathrm{OC}$ administered 1 hour before exenatide was also included. No interaction would be expected during the second treatment period, as OC absorption was likely to be completed prior to the onset of exenatide action. The interaction was assessed after single, as well as multiple doses of $\mathrm{OC}$ to maximise pharmacokinetic information generated from the study.

\section{Methods}

\section{Subjects}

This study was conducted at 1 clinical study center in the United Kingdom. The protocol was approved by the Independent Ethics Committee Plymouth, UK, and was conducted in accordance with the 1975 Declaration of Helsinki, as revised in 2000 [13], and the European Commission's directive on clinical research (2001/20/CE) [14]. Before enrollment, all subjects provided written informed consent. Subjects were required to be taking an OC prior to study entry and be healthy pre-menopausal females, 18 to 45 years old, with a BMI between 19 to $35 \mathrm{~kg} / \mathrm{m}^{2}$. Subjects were excluded from the study if they had diabetes mellitus or had received implanted contraceptives for 6 months or injectable contraceptives for 12 months prior to the study. Grapefruit was restricted within 7 days and concomitant drug therapies that could induce or inhibit CYP3A were not permitted within 14 days before the first drug administration. In case of mild intercurrent illness during the study, ibuprofen and/or anti-emetic medications that would not affect gastrointestinal motility were allowed at the discretion of the investigator. Lifestyle habits of eligible subjects, such as smoking, alcohol consumption, diet, and exercise, were not altered during the study.

\section{Study design}

This was an open-label, 3-period, 3-sequence, randomised crossover study in healthy female subjects who were using OCs prior to study entry (clinicaltrials.gov registration: NCT00254800). The primary objective was to evaluate the effect of exenatide on the multiple-dose PK of a combination oral contraceptive (EE and LV) administered 1 hour before and 30 minutes after the exenatide dose. Up to 40 subjects were to be enrolled to ensure that approximately 18 subjects completed the study. Comparing OC alone and $\mathrm{OC}$ administered 1 hour before exenatide, a sample size of 18 subjects was estimated to provide approximately $90 \%$ power to demonstrate that the $90 \%$ CI of the ratio of 
geometric means for AUC (EE or LV) would be contained within the interval $(0.80,1.25)$. This sample size estimate was based on an intra-subject coefficient of variation of $15 \%$.

The OC combination product (Microgynon $30^{\circledR}$ ) consisted of EE, $30 \mu \mathrm{g}$ and LV, $150 \mu \mathrm{g}$. Prior to starting the active dosing period, screening was conducted over 2 visits. The purpose of the first screening visit, approximately 2 months prior to admission, was to initiate a run-in period either to convert to the study $\mathrm{OC}$ or to synchronise the OC cycle within a cohort of subjects. The second screening visit occurred approximately 21 days prior to the first day of dosing to confirm study eligibility.

Each subject participated in 3 treatment periods, each of 28 days duration: $\mathrm{OC}$ alone, OC 1 hour before exenatide, and $\mathrm{OC}$ approximately 30 minutes after exenatide. Exenatide was self-administered 15 minutes prior to the morning and evening meals at $5 \mu \mathrm{g}$ BID on Days 1 through 4 and increased to $10 \mu \mathrm{g}$ BID on Days 5 through 22. Subjects received a single dose of OC on Day 8 of each treatment period; dosing was omitted on Day 9 to allow for single-dose PK sampling. Subsequently, once-daily doses of OC were resumed on Days 10 through 28. Given that exenatide was administered 15 minutes before meals, OC was administered either 75 minutes before the meal (ie, 1 hour before exenatide) or 15 minutes after the meal (ie, 30 minutes after exenatide), depending on the treatment period. In the $\mathrm{OC}$ alone arm, all multiple $\mathrm{OC}$ doses and the majority of the single $\mathrm{OC}$ doses were given approximately 75 minutes before the meal.

During each treatment period after the first dose of the OC (Day 8), venous blood samples (4 $\mathrm{mL}$ each) were taken pre-dose, and at $0.5,1,1.5,2,2.5,3,3.5,4,4.5,5,6$, $8,10,12,16,24$ and 48 hours post-dose. Blood samples were also taken following multiple doses of the OC (Day 22) pre-dose, and at $0.5,1,1.5,2,2.5,3,3.5,4,4.5,5,6,8$, $10,12,16$ and 24 hours post-dose. At a minimum, subjects were admitted to the Clinical Research Unit (CRU) on Day 7, resident on Day 8, and discharged on Day 9, then admitted again on Day 21, resident on Day 22, and discharged on Day 23. Subjects were required to attend the CRU on Days 10 and 28 as outpatients. At the investigator's discretion, subjects could be resident in the CRU or attend as outpatients after the first exenatide dose (Day 1 ) and upon dose increases to $10 \mu \mathrm{g}$ (Day 5).

\section{Bioanalytical methods}

Human plasma PK samples obtained during this study were analysed at PPD, Richmond, VA, USA. The samples were analysed for EE and LV using validated liquid chromatography with tandem mass spectrometric methods [15]. The lower limit of quantification was $2.00 \mathrm{pg} / \mathrm{mL}$ for $\mathrm{EE}$ and $50.0 \mathrm{pg} / \mathrm{mL}$ for $\mathrm{LV}$; the upper limit of quantification was $200 \mathrm{pg} / \mathrm{mL}$ for $\mathrm{EE}$ and $12500 \mathrm{pg} / \mathrm{mL}$ for LV and. The intra-assay accuracy (\% relative error) during partial validation ranged from $-4.24 \%$ to $0.992 \%$ for LV and from $0.233 \%$ to $2.96 \%$ for EE. The intra-assay precision (\% relative standard deviation) during partial validation ranged from $6.30 \%$ to $8.67 \%$ for $\mathrm{LV}$ and from $4.63 \%$ to $12.1 \%$ for $\mathrm{EE}$.

\section{Pharmacokinetic assessments}

Plasma EE and LV pharmacokinetics were characterised by noncompartmental methods of analysis using WinNonLin Professional Version 5.0.1 (Pharsight, Cary, NC). Plasma concentrations for each OC component were plotted semi-logarithmically against time following single (Day 8) or multiple doses (Day 22). The maximum concentration after single or multiple doses $\left(\mathrm{C}_{\max }\right.$ or $\left.\mathrm{C}_{\max , \text { ss }}\right)$ and the corresponding time of maximum concentration ( $\mathrm{T}_{\max }$ or $\mathrm{T}_{\max }$ ss $)$ were identified from the observed data. After a single dose, the area under the concentration-time curve up to the last sampling time point $\left(\mathrm{AUC}_{0-\mathrm{t}}\right.$, last $)$ was calculated and extrapolated to infinity $\left(\mathrm{AUC}_{0-\infty}\right)$ using the log-linear trapezoidal rule. Following multiple-dose administration of the $\mathrm{OC}$, the area under the curve over the 24-hour post-dose interval $\left(\mathrm{AUC}_{0-\tau, \mathrm{ss}}\right)$ was calculated on Day 22. Additionally, concentrations were tabulated at the 24-hour post-dose scheduled time points following single and multiple doses. These 24 -hour post-dose concentrations are referred to as daily trough concentrations in the remainder of the document.

\section{Statistical methods}

The statistical analysis included all data from subjects who received at least 1 dose of drug, and who had evaluable PK data. The primary PK parameters analysed statistically for $\mathrm{EE}$ and $\mathrm{LV}$ were $\mathrm{AUC}_{0-\infty}$ and $\mathrm{C}_{\max }$ following single-dose administration (Day 8) and $\mathrm{AUC}_{0-\tau \text {, ss }}$ and $\mathrm{C}_{\max \text {, ss }}$ following multiple-dose administration (Day 22). In addition, OC trough concentrations on Day 8 and Day 22 were analysed. PK parameters were log-transformed (base e) prior to analysis. Single- (Day 8) and multipledose (Day 22) PK profiles of EE and LV were assessed separately. A linear mixed-effects model was applied that included subject as a random effect, and treatment, period, and sequence as fixed effects. The differences between treatments and the control (OC alone) were back-transformed to yield the ratio of the LS geometric mean for each PK parameter relative to the control treatment, and the corresponding 90\% CI. An interaction was concluded when the $90 \%$ CI for the ratio of the LS geometric mean was not contained within the pre-specified interval $(0.80,1.25)$. Inter-and intra-subject variability estimates were derived from the mixed-effects model. $\mathrm{T}_{\max }$ was analysed separately for Day 8 and Day 22 using the nonparametric Wilcoxon rank sum test. 


\section{Safety assessments}

Safety was assessed by recording spontaneously reported adverse events and was evaluated at scheduled intervals by physical examination, vital sign measurement (including sitting blood pressure and heart rate), body weight assessments, clinical laboratory tests (including serum biochemistry, hematology, and urinalysis), and 12-lead electrocardiogram recordings.

\section{Results}

\section{Subjects}

A total of 38 healthy female subjects entered the study, 32 of these subjects were randomly assigned to 1 of the 3 sequences. Of the 38 subjects who entered the study, 20 completed the 3 treatment periods, and 18 subjects were withdrawn from the study. The mean (SD) age, weight and body mass index (BMI) for the 32 subjects assigned to treatment were 28 (6.8) years, $69.0(9.3) \mathrm{kg}$ and $25.1(3.2) \mathrm{kg} / \mathrm{m}^{2}$, respectively. The majority $(\mathrm{n}=31)$ of subjects were Caucasian. Twelve subjects were smokers.

Six subjects were withdrawn during the lead-in period, prior to being randomly assigned to a sequence. Four of these 6 subjects withdrew their consent during the runin period because they were unable to participate on the required study dates. One subject was withdrawn due to appendicitis. One subject was withdrawn due to protocol non-compliance. The other 12 subjects were withdrawn after being assigned to treatment: 10 subjects due to adverse events and 2 subjects due to withdrawal of consent. Two of the 12 subjects were withdrawn when $\mathrm{OC}$ was given alone, 5 when $\mathrm{OC}$ was given 1 hour before exenatide, and 5 when $\mathrm{OC}$ was given 30 minutes after exenatide.

\section{Safety and tolerability}

No break-through bleeding was reported during the study. The incidence of adverse events considered to be related to $\mathrm{OC}$ was generally similar across all treatments. An increase in the incidence of adverse events overall was observed with concomitant administration of exenatide and OC compared to administration of $\mathrm{OC}$ alone. The majority of subjects experienced adverse events considered to be related to exenatide. Overall, nausea and vomiting were reported by $91 \%$ and $81 \%$ of subjects, respectively. All cases of nausea were mild or moderate in severity. One case of vomiting was considered to be severe. Twenty subjects received concomitant medication for the treatment and/or prophylaxis of nausea and vomiting, and 6 subjects were withdrawn from the study due to mild or moderate nausea or vomiting. The incidence of vomiting was higher when the $\mathrm{OC}$ was administered 30 minutes after exenatide (74\%), compared to $58 \%$ when administered 1 hour before exenatide; however, these incidences were not statistically different.

Seventeen subjects $(53 \%)$ in the study reported skinrelated adverse events, including injection-site rash (11 subjects) and skin rash (8 subjects). The skin-related adverse events were considered by the investigator to be related to exenatide in all but one of the cases. Two subjects were withdrawn from the study due to rash.

There were no clinically important trends in the serum biochemistry, hematology, urinalysis, blood pressure, heart rate, or 12-lead electrocardiogram data from baseline in each treatment period to follow-up.

\section{Pharmacokinetics}

For subjects who discontinued the study prior to completion of all 3 treatment periods, pharmacokinetics (PK) data generated in other completed periods were included in the PK assessments. Although some subjects experienced vomiting on PK-assessment days, none of these data were excluded from analyses as their concentrations at a scheduled time point were within the prespecified outlier threshold of 3 standard deviations from the mean for the remainder of concentrations at that time point.

\section{Single-dose pharmacokinetics}

Mean plasma concentration time profiles following singledose administration EE and LV are shown in Figures 1 (EE) and 2 (LV). Mean plasma concentration time profiles associated with $\mathrm{OC}$ given 1 hour before exenatide were similar to those observed with $\mathrm{OC}$ alone. Mean plasma EE and plasma LV concentration time profiles following OC administration 30 minutes after exenatide were characterised by a reduced $\mathrm{C}_{\max }$ and delayed $\mathrm{T}_{\max }$.

Statistical comparisons for single-dose PK parameters are shown in Table 1 (EE) and Table 2 (LV). Consistent with the graphical evaluations, concomitant exenatide

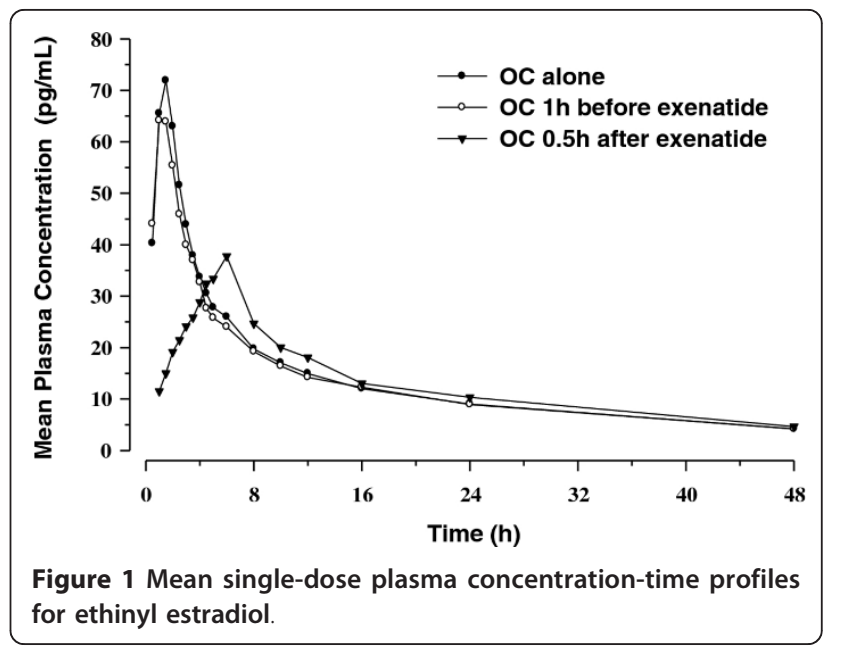




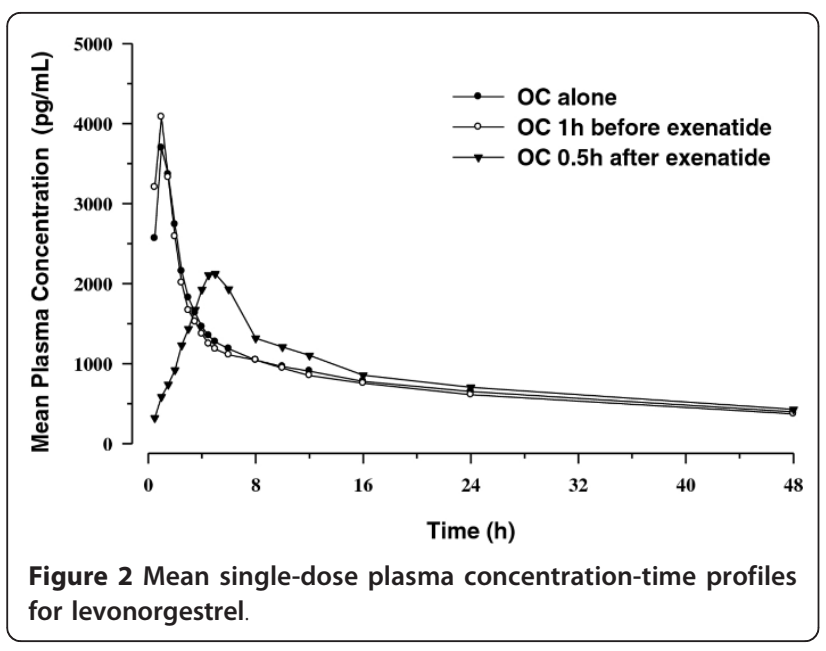

administration did not alter the bioavailability (as measured by $\mathrm{AUC}_{0-\infty}$ ) of $\mathrm{EE}$ or $\mathrm{LV}$, as the $90 \%$ confidence intervals (CI) for the ratios of the least-squares (LS) geometric means were contained within the pre-specified "no effect" range (0.8 to 1.25). Administration of OC 1 hour before exenatide did not result in a change in $\mathrm{C}_{\text {max }}$ for either EE or LV, but administration of OC 30 minutes after exenatide resulted in reductions in $C_{\max }$ of $46 \%$ and $41 \%$ for EE and LV, respectively, compared to OC given alone. These reductions in $\mathrm{C}_{\max }$ were accompanied by median $\mathrm{T}_{\max }$ increases of 4.05 and 3.75 hours for EE and LV, respectively. No differences in trough concentrations of either EE or LV were observed when $O C$ was administered 1 hour before exenatide. Increases in trough concentrations for both $\mathrm{EE}(24 \%)$ and LV (15\%) were observed when OC was administered 30 minutes after exenatide.

\section{Multiple-dose pharmacokinetics}

Mean plasma concentration time profiles following repeated daily dosing (Day 22) are presented in Figures 3 (EE) and $4(\mathrm{LV})$. Similar to the single-dose PK evaluations, results from the multiple-dose $\mathrm{PK}$ assessments demonstrated that administration of OC 30 minutes after exenatide reduced $C_{\max }$ and delayed $T_{\max }$ for both $\mathrm{EE}$ and LV compared with OC given alone. As with the single-dose period, PK differences following repeated daily dosing were mainly evident in the absorptive phase. When OC was given 1 hour before exenatide, no changes in the OC PK profiles were observed.

Between-treatment statistical comparisons for multiple-dose PK parameters are shown in Table 1 (EE) and Table $2(\mathrm{LV})$. As with the single-dose data, regardless of timing of exenatide administration relative to OC dosing, no changes in bioavailability $\left(\mathrm{AUC}_{0-\tau}\right.$, ss $)$ of either $\mathrm{EE}$ or LV were observed after concomitant repeated daily administration of $\mathrm{OC}$ and exenatide. Compared to OC given alone, repeated daily administration of OC 1 hour before exenatide resulted in a small reduction in $\mathrm{EE} \mathrm{C}_{\max }$ of approximately $15 \%$ but did not alter $\mathrm{LV} \mathrm{C}_{\max }$. Reductions in $\mathrm{C}_{\max }$ were more notable when the $\mathrm{OC}$ was administered 30 minutes after exenatide. Repeated daily doses of OC given 30 minutes after exenatide reduced $\mathrm{EE}$ and $\mathrm{LV} \mathrm{C}_{\max }$ by $45 \%$ and $27 \%$, respectively, compared with OC given alone. Median $\mathrm{T}_{\max }$ was also delayed by 3 hours and 3.5 hours for EE and LV, respectively, compared with $\mathrm{OC}$ alone. As observed in the single-dose results, increases in trough concentrations for both $\mathrm{EE}$ (20\%) and LV (11\%) were observed when OC was administered 30 minutes after exenatide. No differences in trough concentrations of EE or LV were observed when $\mathrm{OC}$ was administered 1 hour before exenatide.

\section{Discussion}

In this pharmacokinetic drug-interaction study, coadministration with exenatide did not affect mean plasma AUC of EE and LV under single- or multiple-dose conditions. Furthermore, no decreases in trough concentrations were observed. Additionally, no substantive changes in PK profiles were observed when the OC was administered 1 hour before exenatide. A small effect was observed $(90 \% \mathrm{CI} ; 0.78,0.93)$ in $\mathrm{C}_{\max }$ when OC was administered alone, however, as the lower confidence bound is close to 0.8 , this shift is not likely to be of clinical relevance. Reductions in peak OC concentrations, accompanied by delayed $\mathrm{T}_{\max }$, were observed with OC administered 30 minutes after exenatide. This effect of exenatide on OC absorption would be expected, due to its action to slow gastric emptying, and is consistent with prior drug-drug interaction studies of exenatide with other orally administered drugs [8-12].

Drug-drug interaction studies with oral contraceptives are generally conducted to understand the potential for concomitantly administered drugs to induce or inhibit cytochrome P450 isoenzyme (CYP) mediated oxidative metabolism of EE [16]. While EE is metabolised by both CYP3A-mediated oxidative metabolism and Phase II metabolism, including glucuronidation and sulfation, the most clinically relevant metabolic pathway is induction or inhibition of CYP3A. Drugs that decrease EE bioavailability via CYP3A induction may potentially result in reduced OC efficacy. The observation that OC AUC concentrations were unaltered in this study confirmed that exenatide does not induce CYP3A. However, the clinical relevance of $\mathrm{C}_{\max }$ reductions seen in the study (up to $46 \%$ for $\mathrm{EE}$ and $41 \%$ for $\mathrm{LV}$ ) requires additional consideration.

Reports of large inter-subject variability in concentrations of OCs, with several-fold differences in serum concentrations likely due to inter-individual differences in first-pass metabolism, have been described in the 
Table 1 Ethinyl Estradiol Single- and Multiple-dose Pharmacokinetics: Comparison of Mean Pharmacokinetic Parameters Across Treatments

\begin{tabular}{|c|c|c|c|c|c|}
\hline & & \multicolumn{2}{|r|}{ Single Dose } & \multicolumn{2}{|c|}{ Multiple Dose } \\
\hline & & $\begin{array}{l}\text { LS Geometric } \\
\text { Mean }\end{array}$ & $\begin{array}{c}\text { Comparison to OC alone: } \\
\text { Ratio }(90 \% \mathrm{Cl})\end{array}$ & $\begin{array}{l}\text { LS Geometric } \\
\text { Mean }\end{array}$ & $\begin{array}{c}\text { Comparison to } \mathrm{OC} \text { alone: } \\
\text { Ratio }(90 \% \mathrm{Cl})\end{array}$ \\
\hline \multirow[t]{3}{*}{ AUC $(p g \cdot h / m L)$} & OC alone & 718.89 & - & 761.06 & - \\
\hline & $\begin{array}{l}1 \mathrm{~h} \text { before } \\
\text { exenatide }\end{array}$ & 691.69 & $0.96(0.91,1.02)$ & 716.70 & $0.94(0.88,1.01)$ \\
\hline & $\begin{array}{l}0.5 \mathrm{~h} \text { after } \\
\text { exenatide }\end{array}$ & 692.56 & $0.96(0.91,1.02)$ & 734.01 & $0.96(0.90,1.04)$ \\
\hline \multirow[t]{3}{*}{$C_{\max }(p g / m L)$} & OC alone & 72.18 & - & 102.15 & - \\
\hline & $\begin{array}{l}1 \mathrm{~h} \text { before } \\
\text { exenatide }\end{array}$ & 65.49 & $0.91(0.83,0.99)$ & 87.09 & $0.85(0.78,0.93)$ \\
\hline & $\begin{array}{l}0.5 \mathrm{~h} \text { after } \\
\text { exenatide }\end{array}$ & 38.64 & $0.54(0.49,0.58)$ & 56.32 & $0.55(0.50,0.60)$ \\
\hline \multirow{3}{*}{$\begin{array}{l}\text { 24-h concentration (pg/ } \\
\mathrm{mL} \text { ) }\end{array}$} & OC alone & 8.27 & - & 14.64 & - \\
\hline & $\begin{array}{l}1 \mathrm{~h} \text { before } \\
\text { exenatide }\end{array}$ & 8.13 & $0.98(0.92,1.05)$ & 15.03 & $1.03(0.95,1.11)$ \\
\hline & $\begin{array}{l}0.5 \mathrm{~h} \text { after } \\
\text { exenatide }\end{array}$ & 10.25 & $1.24(1.16,1.33)$ & 17.52 & $1.20(1.10,1.30)$ \\
\hline \multirow[t]{3}{*}{$\mathrm{T}_{\max }$ median (range) (h) } & OC alone & - & $1.50(0.50-2.50)$ & - & - \\
\hline & $\begin{array}{l}1 \mathrm{~h} \text { before } \\
\text { exenatide }\end{array}$ & - & $1.50(0.50-2.00)$ & - & - \\
\hline & $\begin{array}{l}0.5 \mathrm{~h} \text { after } \\
\text { exenatide }\end{array}$ & - & $6.00(2.00-6.13)$ & - & - \\
\hline \multirow{3}{*}{$\begin{array}{l}t_{1 / 2} \text { geometric mean } \\
\text { (range) }(h)\end{array}$} & OC alone & - & $19.5(13.8-32.1)$ & - & - \\
\hline & $\begin{array}{l}1 \mathrm{~h} \text { before } \\
\text { exenatide }\end{array}$ & - & $18.9(14.0-30.1)$ & - & - \\
\hline & $\begin{array}{l}0.5 \mathrm{~h} \text { after } \\
\text { exenatide }\end{array}$ & - & $17.4(8.78-31.9)$ & - & - \\
\hline
\end{tabular}

literature. Goldzieher et al. [17] have reported that differences in EE concentrations have been shown to vary between ethnic groups, as well as across study sites and, even for a given individual, EE AUCs can vary by almost a factor of 4 . This same study group has also reported the existence of high intra- and inter-subject variability in the pharmacokinetics of progestins such as LV [17]. Thus, the magnitude of $C_{\text {max }}$ reduction observed in the present study was likely within the inherent PK variability of the OC components.

The current study did not measure OC pharmacodynamics (eg, follicle-stimulating hormone or luteinizing hormone concentrations); therefore, a direct within-study clinical relationship with the observed $C_{\max }$ reduction cannot be derived. Importantly, no break-through bleeding was reported. Break-through bleeding may be associated with low concentrations of estrogen-progestin $[16,18]$.

A review of prescription labeling indicates that drug interactions with OCs are deemed to be clinically important, and dosage adjustments are thereby recommended, only when associated with a significant reduction in OC AUC. However, there does not appear to be a well- accepted minimum threshold concentration for pharmacological activity. Importantly, in this study OC AUC was unchanged. Furthermore, trough concentrations did not decrease in the presence of exenatide suggesting that sub-therapeutic concentrations were unlikely.

In the absence of conclusive literature on the exposureefficacy relationships of OCs, other aspects of OC PK/PD were considered to help understand the possible clinical relevance of the $C_{\max }$ decrease observed in the present study. In food-effect studies, $\mathrm{OC} \mathrm{C}_{\max }$ reductions of up to $40 \%$ are commonly observed without changes in AUC. Despite this potential effect of food on $\mathrm{C}_{\max }$, OCs are generally recommended to be taken without regard to food [19], suggesting that PK changes observed in this study are not likely to be clinically relevant. In the current study, the effect of food consumption on the OC PK cannot be clearly differentiated from the effects of exenatide; however, these data reflect conditions under which the 2 drugs are likely to be co-administered, given that exenatide is to be administered within an hour of meals. Thus, in consideration of indirect evidence from food-effect studies, the large inherent variability in OC concentrations, and the 
Table 2 Levonorgestrel Single- and Multiple-dose Pharmacokinetics: Comparison of Mean Pharmacokinetic Parameters Across Treatments

\begin{tabular}{|c|c|c|c|c|c|}
\hline & & \multicolumn{2}{|r|}{ Single Dose } & \multicolumn{2}{|c|}{ Multiple Dose } \\
\hline & & $\begin{array}{l}\text { LS Geometric } \\
\text { Mean }\end{array}$ & $\begin{array}{c}\text { Comparison to OC alone: } \\
\text { Ratio }(90 \% \mathrm{Cl})\end{array}$ & $\begin{array}{l}\text { LS Geometric } \\
\text { Mean }\end{array}$ & $\begin{array}{c}\text { Comparison to OC alone: } \\
\text { Ratio }(90 \% \mathrm{Cl})\end{array}$ \\
\hline \multirow[t]{3}{*}{ AUC $(p g \cdot h / m L)$} & OC alone & 55698.79 & - & 72974.62 & - \\
\hline & $\begin{array}{l}1 \mathrm{~h} \text { before } \\
\text { exenatide }\end{array}$ & 53530.64 & $0.96(0.90,1.03)$ & 72952.67 & $1.00(0.92,1.09)$ \\
\hline & $\begin{array}{l}0.5 \mathrm{~h} \text { after } \\
\text { exenatide }\end{array}$ & 60591.89 & $1.09(1.01,1.17)$ & 76344.29 & $1.05(0.96,1.14)$ \\
\hline \multirow[t]{3}{*}{$C_{\max }(p g / m L)$} & OC alone & 3882.56 & - & 6598.95 & - \\
\hline & $\begin{array}{l}1 \mathrm{~h} \text { before } \\
\text { exenatide }\end{array}$ & 4061.86 & $1.05(0.94,1.16)$ & 6657.22 & $1.01(0.92,1.10)$ \\
\hline & $\begin{array}{l}0.5 \mathrm{~h} \text { after } \\
\text { exenatide }\end{array}$ & 2284.25 & $0.59(0.53,0.65)$ & 4800.68 & $0.73(0.67,0.79)$ \\
\hline \multirow{3}{*}{$\begin{array}{l}\text { 24-h concentration (pg/ } \\
\mathrm{mL})\end{array}$} & OC alone & 600.88 & - & 2136.51 & - \\
\hline & $\begin{array}{l}1 \mathrm{~h} \text { before } \\
\text { exenatide }\end{array}$ & 571.47 & $0.95(0.89,1.02)$ & 2173.05 & $1.02(0.93,1.11)$ \\
\hline & $\begin{array}{l}0.5 \mathrm{~h} \text { after } \\
\text { exenatide }\end{array}$ & 691.10 & $1.15(1.07,1.23)$ & 2367.68 & $1.11(1.01,1.21)$ \\
\hline \multirow[t]{3}{*}{$\mathrm{T}_{\max }$ median (range) (h) } & OC alone & - & $1.00(0.50-2.07)$ & - & - \\
\hline & $\begin{array}{l}1 \mathrm{~h} \text { before } \\
\text { exenatide }\end{array}$ & - & $0.92(0.50-1.50)$ & - & - \\
\hline & $\begin{array}{l}0.5 \mathrm{~h} \text { after } \\
\text { exenatide }\end{array}$ & - & $4.75(3.00-6.02)$ & - & - \\
\hline \multirow{3}{*}{$\begin{array}{l}t_{1 / 2} \text { geometric mean } \\
\text { (range) (h) }\end{array}$} & OC alone & - & $33.6(20.0-78.5)$ & - & - \\
\hline & $\begin{array}{l}1 \mathrm{~h} \text { before } \\
\text { exenatide }\end{array}$ & - & $32.1(19.8-55.7)$ & - & - \\
\hline & $\begin{array}{l}0.5 \mathrm{~h} \text { after } \\
\text { exenatide }\end{array}$ & - & $32.6(17.9-72.4)$ & - & - \\
\hline
\end{tabular}

fact that product labeling suggests changes in OC dosage only in the presence of large changes in OC AUC alone, we conclude that the PK changes observed in the present study are not likely to have clinical implications.

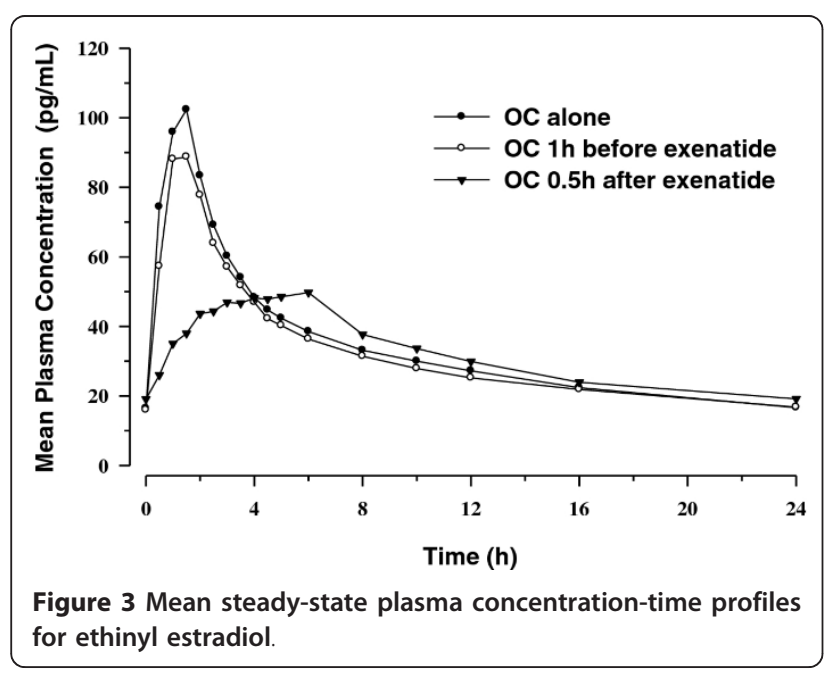

Concomitant administration of exenatide and a combination $\mathrm{OC}$ to healthy female subjects resulted in a high incidence of gastrointestinal adverse events. This study used 4-day dose initiation at $5 \mu \mathrm{g}$ BID, rather than 4 weeks as recommended for exenatide dosing [20], and

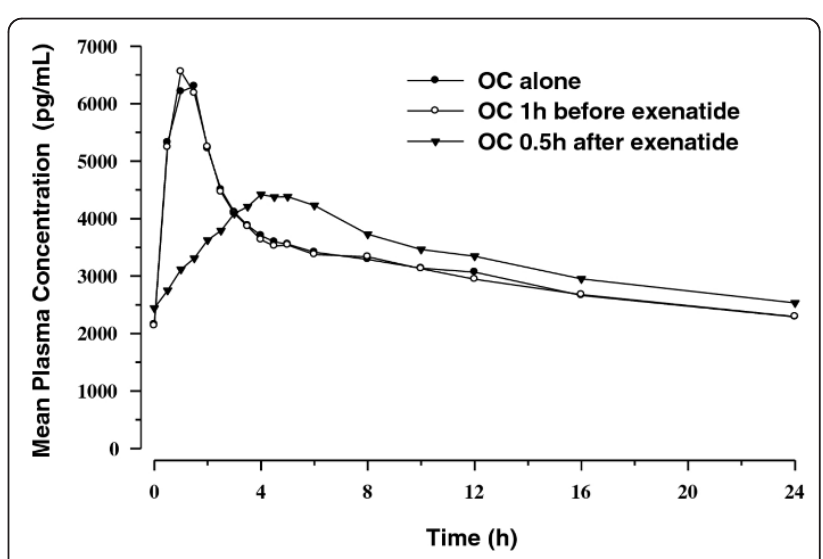

Figure 4 Mean steady-state plasma concentration-time profiles for levonorgestrel 
this may have contributed to the poor tolerability. Furthermore, cross-study comparisons have suggested that exenatide administration may result in a higher incidence of gastrointestinal adverse events in healthy subjects compared with patients with type 2 diabetes [8]. More specifically, the high incidence of nausea and vomiting observed in the present drug-drug interaction study has not been observed in large clinical trials of exenatide-treated patients with type 2 diabetes [21-24]. Additionally, although there were no unexpected adverse events observed in this study, the incidence of skinrelated adverse events among exenatide-treated subjects (53\%) was higher than the incidence observed in previous clinical studies [21-24].

\section{Conclusions}

This study evaluated the potential effect of subcutaneously administered exenatide (10 $\mu \mathrm{g}$ BID) on the single and multiple doses pharmacokinetics of a combination OC (EE/ LV). No pharmacokinetic interaction was observed when the $\mathrm{OC}$ was administered an hour prior to exenatide treatment. However, administration of the OC 30 minutes after exenatide therapy was associated with a reduced $\mathrm{C}_{\max }$ with a delayed $\mathrm{T}_{\max }$ of EE and LV. The observed reduction in $\mathrm{C}_{\max }$ is likely of limited importance as coadministration of exenatide did not cause significant changes in the overall bioavailability of EE or LV after single or multiple doses. For oral medications that are dependent on threshold concentrations for efficacy, such as contraceptives and antibiotics, patients should be advised to take those drugs at least 1 hour before exenatide injection.

\section{Acknowledgements}

The contributing coauthors would like to thank the clinical trial investigators and their staffs at the participating research sites, Shobha Reddy for her assistance with the analyses, and Laura Bean Warner of i3Statprobe for her assistance with preparing this manuscript.

\section{Author details \\ ${ }^{1}$ Eli Lilly and Company, Lilly Corporate Center, Indianapolis, IN, USA. ${ }^{2}$ Eli Lilly and Company, Lilly Research Center, Earl Wood Manor, Windlesham, Surrey} GU20 6PH, UK.

\section{Authors' contributions}

PAK, MES, HL, MM, and KM participated in the design of the study. PAK, HL, MES, and JN have been involved in drafting the manuscript. All authors have participated in the analysis and interpretation of data, and the critical revision for important intellectual content. All authors approved the version to be published.

\section{Competing interests}

This study was sponsored by Amylin Pharmaceuticals, Inc. and Eli Lilly and Company. Sponsors were involved in the study design, protocol development, and the collection, review, and analysis of the data. Authors are employees of Eli Lilly and Company.

Received: 23 September 2011 Accepted: 19 March 2012 Published: 19 March 2012
References

1. Reddy S, Park S, Fineman M, Jay L, Carter M, Reynolds L, Sanburn N, Kothare PA: Clinical pharmacokinetics of exenatide in patients with type 2 diabetes [abstract]. AAPS J 2005, 7:M1285.

2. Copley K, McCowen K, Hiles R, Nielsen LL, Young A, Parkes DG: Investigation of exenatide elimination and its in vivo and in vitro degradation. Curr Drug Metabol 2006, 7:367-374

3. Kolterman OG, Buse JB, Fineman MS, Gaines E, Heintz S, Bicsak TA, Taylor K, Kim D, Aisporna M, Wang Y, Baron AD: Synthetic exendin-4 (exenatide) significantly reduces postprandial and fasting plasma glucose in subjects with type 2 diabetes. J Clin Endocrinol Metab 2003, 88:3082-3089.

4. Kolterman OG, Kim DD, Shen L, Ruggles JA, Nielsen LL, Fineman MS, Baron AD: Pharmacokinetics, pharmacodynamics, and safety of exenatide in patients with type 2 diabetes mellitus. Am J Health Syst Pharm 2005, 62:173-181.

5. Linnebjerg H, Park S, Kothare PA, Trautmann ME, Mace K, Fineman M, Wilding I, Nauck M, Horowitz M: Effect of exenatide on gastric emptying and relationship to postprandial glycemia in type 2 diabetes. Regul Pept 2008, 151:123-129.

6. Verdich C, Flint A, Gutzwiller JP, Näslund E, Beglinger C, Hellström PM, Long SJ, Morgan LM, Holst JJ, Astrup A: A meta-analysis of the effect of glucagon-like peptide-1 (7-36) amide on ad libitum energy intake in humans. J Clin Endocrinol Metab 2001, 86:4382-4389.

7. Edwards CM, Stanley SA, Davis R, Brynes AE, Frost GS, Seal LJ, Ghatei MA, Bloom SR: Exendin-4 reduces fasting and postprandial glucose and decreases energy intake in healthy volunteers. Am J Physiol Endocrinol Metab 2001, 281:E155-E161.

8. Kothare PA, Soon DK, Linnebjerg H, Park S, Chan C, Yeo A, Lim M, Mace KF, Wise SD: Effect of exenatide on the steady-state pharmacokinetics of digoxin. J Clin Pharmacol 2005, 45:1032-1037.

9. Soon D, Kothare PA, Linnebjerg H, Park S, Yuen E, Mace KF, Wise SD: Effect of exenatide on the pharmacokinetics and pharmacodynamics of warfarin in healthy Asian men. J Clin Pharmacol 2006, 46:1179-1187.

10. Kothare PA, Linnebjerg H, Skrivanek Z, Reddy S, Mace K, Pena A, Han J, Fineman M, Mitchell M: Exenatide effects on statin pharmacokinetics and lipid response. Int J Clin Pharmacol Ther 2007, 45:114-120.

11. Linnebjerg $H$, Kothare P, Park S, Mace K, Mitchell M: The effect of exenatide on lisinopril pharmacodynamics and pharmacokinetics in patients with hypertension. Int J Clin Pharmacol Ther 2009, 47:651-658.

12. Blase E, Taylor K, Gao HY, Wintle M, Fineman M: Pharmacokinetics of an oral drug (acetaminophen) administered at various times in relation to subcutaneous injection of exenatide (exendin-4) in healthy subjects. J Clin Pharmacol 2005, 45:570-577.

13. Zhang $H$, Cui D, Wang B, Han YH, Balimane P, Yang Z, Sinz M, Rodrigues AD: Pharmacokinetic drug interactions involving 17[alpha]ethinylestradiol: a new look at an old drug. Clin Pharmacokinet 2007, 46:133-157.

14. Goldzieher JW, Stanczyk FZ: Oral contraceptives and individual variability of circulating levels of ethinyl estradiol and progestins. Contraception 2008, 78:4-9.

15. Hall SD, Wang Z, Huang SM, Hamman MA, Vasavada N, Adigun AQ, Hilligoss JK, Miller M, Gorski JC: The interaction between St John's wort and an oral contraceptive. Clin Pharmacol Ther 2003, 74:525-535.

16. Boyd RA, Zegarac EA, Eldon MA: The effect of food on the bioavailability of norethindrone and ethinyl estradiol from norethindrone acetate/ ethinyl estradiol tablets intended for continuous hormone replacement therapy. J Clin Pharmacol 2003, 43:52-58.

17. Byetta (package insert). San Diego, CA: Amylin Pharmaceuticals, Inc; 2008 [http://documents.byetta.com/Byetta_Pl.pdf].

18. Buse JB, Henry RR, Han J, Kim DD, Fineman MS, Baron AD: Exenatide-113 Clinical Study Group: Effects of exenatide (exendin-4) on glycemic control over 30 weeks in sulfonylurea-treated patients with type 2 diabetes. Diabetes Care 2004, 27:2628-2635.

19. DeFronzo RA, Ratner RE, Han J, Kim DD, Fineman MS, Baron AD: Effects of exenatide (exendin-4) on glycemic control and weight over 30 weeks in metformin-treated patients with type 2 diabetes. Diabetes Care 2005, 28:1092-1100.

20. Kendall DM, Riddle MC, Rosenstock J, Zhuang D, Kim DD, Fineman MS, Baron AD: Effects of exenatide (exendin-4) on glycemic control over 30 weeks in patients with type 2 diabetes treated with metformin and a sulfonylurea. Diabetes Care 2005, 28:1083-1091. 
21. Klonoff DC, Buse JB, Nielsen LL, Guan X, Bowlus CL, Holcombe JH, Wintle ME, Maggs DG: Exenatide effects on diabetes, obesity, cardiovascular risk factors and hepatic biomarkers in patients with type 2 diabetes treated for at least 3 years. Curr Med Res Opin 2008, 24:275-286.

22. World Medical Association Declaration of Helsinki: ethical principles for medical research involving human subjects. JAMA 2000, 284:3043-3045.

23. Directive 2001/20/EC of the European Parliament and of the Council of 4 April 2001. The European Parliament and the Council of the European Union;[http://www.ema.europa.eu/ema/index.jsp?curl=pages/includes/ document/document_detail.jsp?

webContentld=WC500011204\&murl=menus/document_library/ document_library.jsp\&mid=WC0b01ac058009a3dc].

24. Li W, Li YH, Li AC, Zhou S, Naidong W: Simultaneous determination of norethindrone and ethinyl estradiol in human plasma by high performance liquid chromatography with tandem mass spectrometryexperiences on developing a highly selective method using derivatization reagent for enhancing sensitivity. J Chromatogr B Analyt Technol Biomed Life Sci 2005, 825:223-232.

\section{Pre-publication history}

The pre-publication history for this paper can be accessed here: http://www.biomedcentral.com/1472-6904/12/8/prepub

doi:10.1186/1472-6904-12-8

Cite this article as: Kothare et al:: Effect of exenatide on the pharmacokinetics of a combination oral contraceptive in healthy women: an open-label, randomised, crossover trial. BMC Clinical Pharmacology 2012 $12: 8$.

\section{Submit your next manuscript to BioMed Central} and take full advantage of:

- Convenient online submission

- Thorough peer review

- No space constraints or color figure charges

- Immediate publication on acceptance

- Inclusion in PubMed, CAS, Scopus and Google Scholar

- Research which is freely available for redistribution

Submit your manuscript at www.biomedcentral.com/submit 